\title{
HACIA UN PERFIL DEL JOVEN CAMPESINO PERUANO
}

\section{Imelda Vega-Centeno B.}

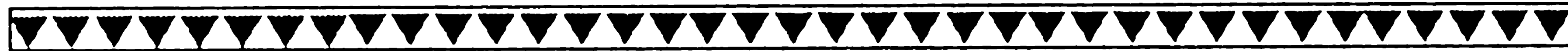

EN ESTE TRABAJO DE REFLEXIÓN en torno al perfil del joven campesino peruano fuimos introducidos por nuestras propias preguntas, pues, al haber investigado en otras ocasiones sobre la juventud en medio urbano, intuíamos que los comportamientos, prácticas y actitudes de los jóvenes en el medio rural debían ser diferentes a los que habíamos encontrado en las ciudades, ya que se trata de un conjunto de prácticas culturales producidas dentro de medios culturalgeneracionales completamente distintos, y dentro de situaciones socioeconómicas mucho más tensas y angustiantes ${ }^{1}$.

Recientemente, al entrevistar a algunos conocedores del medio y problemática rural del país y preguntarles qué y cómo era un joven campesino, me sorprendí de encontrar en ellos sólo un cúmulo de preguntas: quienes yo pensaba que podían aportarme una visión global del joven campesino me respondieron con más preguntas y esperaban de mí, como investigadora, las respuestas que ellos no habían obtenido $(E / 36,37)$. Quedaba pendiente la respuesta.

¿Qué es un joven campesino?, ¿quiénes son?, ¿los jóvenes se quedan aún en el campo?, ¿quiénes son los que migran 
IMELDA VEGA-CENTENOB.

del campo y por qué?, ¿cómo migran hoy los jóvenes?, ¿es una decisión de grupo o individual?, ¿es lo mismo un campesino que un joven trabajador rural?, ¿qué queda del sindicalismo agrario y de la organización campesina de los años setenta? Estas eran, entre otras, las preguntas que los «expertos" en campesinado se habían hecho y que no habían encontrado respuesta.

En un trabajo nuestro publicado en 1984 habíamos elaborado ciertas hipótesis interpretativas sobre cómo era visto el joven, sea campesino, de medio barrial, de sector burgués, etc., por los campos de socialización en que se desenvuelve y a través de los cuales se inserta en un medio social y, por otro lado, cómo es visto por el sistema de producción dominante ${ }^{2}$. Esta distinción tipológica fue hecha teniendo en cuenta que la juventud es el período de edad en que se complejizan los campos de socialización; edad en la que, contrariamente al niño, que se socializa únicamente en medio de la familia, el joven se socializa al mismo tiempo en la escuela, el trabajo, el tiempo libre u ocio, además de su propio medio familiar.

Por esta razón, cuando tuvimos finalmente la oportunidad de trabajar con jóvenes de medio rural, comprometidos en un movimiento de formación por la acción que tiene a los jóvenes campesinos como población-objetivo, fue para nosotros la oportunidad privilegiada para cuestionar la realidad del joven campesino con las hipótesis elaboradas a lo largo de diversos trabajos en medio urbano y, de esta manera, poder poner en evidencia tanto la especificidad como aquello que es común a los jóvenes, vengan de donde provengan, según el medio socio-cultural en que se desenvuelven ${ }^{3}$.

El presente artículo tiene como referente dicho trabajo de evaluación. Las fuentes primarias que utilizamos son tanto las reuniones como las entrevistas ( $\mathrm{CF}$. $\mathrm{R} / \mathrm{nE}, \mathrm{E} / \mathrm{nE}$ ) que realizamos entonces, así como nuestra participación en la reunión de la coordinación nacional de la JARC en agosto pasado, donde pudimos reflexionar conjuntamente con los dele- 
gados de las bases sobre la situación del joven campesino peruano. Teniendo en cuenta nuestras inquietudes de conocer al joven campesino, al encontrarnos con los grupos de base $^{t}$, estos fueron cuestionados en torno al conjunto de camlpos de socialización, para poder esclarecer la función de los mismos en la vida de los jóvenes concretos. A su vez, cuando involucramos a los participantes de la IX Coordinación Nacional de la JARC en este proceso reflexivo, les propusimos el mismo cuadro de análisis ${ }^{5}$.

\section{Notas sobre el Perú rural}

A FINES DEL SEGUNDO MILENIO

Hacer trabajo de campo en medio rural, en la era post-Sendero Luminoso, nos coloca ante viejas y siempre nuevas preguntas. Por ejemplo, al visitar la costa de la región Libertadores-Wari, no pudimos menos que percibir la presencia de la ola migratoria de los Andes ayacuchanos, producto de la guerra que acabamos de vivir. Este hecho nos confronta con las siempre vigentes tesis del Dr. Javier Pulgar Vidal': "La apropiación del espacio, por parte de los antiguos peruanos siempre fue transversal», por ello los incas de Cusco podían comer pescado fresco, que venía de la zona de Puerto Inca en Arequipa; y los nascas podían bordar sus mantos con plumas de aves amazónicas, traídas desde las selvas altas de Ayacucho. Desde hace siglos, las montañas andinas, el monte amazónico y los desiertos costeños están atravesados por miles de caminos de herradura; estos caminos encontraron nueva utilidad cuando, aterrorizados por la secuela de sangre y muerte que dejaban a su paso las incursiones de Sendero Luminoso, el pueblo pobre, atrapado entre dos fuegos (Sendero Luminoso y las Fuerzas Armadas), encontró en las rutas trazadas por sus abuelos las vías (desconocidas y bien conocidas al mismo tiempo), para huir de la muerte y salvar a sus familias. 
IMELDA VEGA-CENTENO B.

Departamentos como Ica ${ }^{7}$ son lugares de acogida a migrantes. Un $60 \%$ de la población total del mismo no ha nacido en Ica, lo que le imprime a este departamento una dinámica poblacional sumamente ágil. El crecimiento del sector informal, del área de servicios personales, así como la explosión educativa de sus colegios e institutos superiores, nos demuestra que nos encontramos ante una población joven y con una dinámica poblacional creciente. Este proceso migratorio afecta sobre todo a las ciudades, el campo no ha visto incrementar su población, y si lo hizo fue sólo temporalmente. Persiste en las zonas de Nasca la migración temporal para determinadas campañas agrícolas y para el pastoreo, inclusive algunos observadores afirman que actualmente, frente al fenómeno del retorno de los migrantes por el terrorismo, lo que queda en el campo son sólo las migraciones andinas temporales, que no afectarán a la larga la dinámica poblacional de la región (E/1, E/6).

Contrariamente, en las ciudades y en los sectores más avanzados del campo, así como en las zonas más pobres de éste último, se da el fenómeno de la emigración, ya que los jóvenes salen del campo para estudiar y la formación que reciben en la ciudad no les asegura empleo en sus pueblos de origen. Por ejemplo, la oferta de empleo agroindustrial en Chincha es pequeña, a pesar de que esta actividad ha significado un enorme avance en la región, incentivada por la actividad agroexportadora. No hay oferta de empleo, los sueldos ofrecidos son mínimos, no hay inversiones en el campo y la presencia del capital extranjero en la agricultura de exportación implica mayor explotación del trabajador rural nacional, quien se encuentra, además, desprotegido por los organismos estatales. Las condiciones socioeconómicas que alimentaron al fenómeno terrorista persisten, y el campo iqueño se vuelve expulsivo para sus jóvenes generaciones.

Los jóvenes jarcistas insistían en la importancia de la formación para el trabajo y el desarrollo de proyectos productivos alternativos, como medios para frenar la migración 
indiscriminada $(R / 8, R / 9)$, puesto que son conscientes de que las ofertas de trabajo en la ciudad no son formidables, que frecuentemente tampoco tendrán en cuenta el nivel de formación profesional que han alcanzado y que además en la ciudad estarán sometidos a las tentaciones del dinero fácil proveniente del narcotráfico $(\mathrm{R} / 5, \mathrm{R} / 8)$.

Cuando visitamos el departamento de San Martín, nuevamente nos confrontamos con el masivo fenómeno migratorio. Esta región ha sido poblada de modo desordenado por los migrantes de la costa y de la sierra norte, provenientes en su mayoría de Chiclayo, Trujillo, Jaén, Chota y Cutervo; los cuales, atraídos por un discurso político que mostraba a la Amazonía como un inmenso territorio, rico y con tierras de libre disponibilidad, abandonaron sus pueblos de origen (fundamentalmente los valles de la costa) y se trasladaron a la Amazonía, donde hicieron lo que siempre habían hecho: introdujeron en la selva el cultivo del maíz, arroz, algodón y otras especies rentables en la costa. Para hacerlo, el migrante costeño y serrano depredó el monte amazónico, destruyó bosques y provocó zonas de inundaciones en las riveras de los ríos, con consecuencias catastróficas para el medio ambiente, poniendo en serio peligro sus propias vidas por los riesgos de avalanchas, desbordes y derrumbes que inconscientemente provocaron $(\mathrm{E} / 14,16)$. Actualmente, la mayoría de las instituciones de la región conocen las consecuencias de estos comportamientos inconscientes de los migrantes, pero no todos los campesinos ribereños de la Amazonía han sido informados ni instruidos sobre los peligros que conllevan estos comportamientos hacia el medio ambiente. La historia del ecocidio, por tanto, se sigue repitiendo.

Por ello, la mayoría de los organismos estatales, así como las ONGs y las municipalidades, están empeñados en diversificar la producción, introduciendo productos económicamente rentables y que no dañen al medio ambiente (E/ 16). Los agricultores que se interesan por los cultivos alter- 
IMELDA VEGA-CENTENO B.

nativos quisieran abarcar también todo el proceso productivo, para no terminar presos de los intermediarios ni de los circuitos cerrados de comercialización y exportación. La falta de políticas estatales que privilegien la agricultura de la zona provoca situaciones muy arriesgadas, pues los agricultores que han abandonado el cultivo de la coca no tienen otra salida que volver a los cultivos que hicieron tradicionalmente en los valles costeños donde nacieron. Su actividad rural termina dañando el medio ambiente y los coloca en situación de riesgo, situación que se agrava por la falta de vías de acceso y de comunicación en esta región (E/15, 16).

Por otro lado, visitar las provincias altas de Cusco y buena parte del departamento de Puno nos confrontó con una región culturalmente (tanto quechua como aimara) caracterizada por una dinámica muy activa y por la supervivencia de culturas ancestrales que dan riqueza y complejidad a la región. Siempre se ha dicho que los puneños migraban hacia Tacna y Moquegua porque eran buenos comerciantes, afirmación que no tiene en cuenta que el país aimara ancestralmente combinó el dominio de la zona lacustre con posesiones en la selva alta y en la costa, donde desarrollaron tareas temporales de explotación agrícola y de pesca; recurriendo a la apropiación transversal del espacio de los antiguos peruanos, dominando así una geografía difícil con el uso racional de los pisos ecológicos. Hablar de los «aimaras del desierto de Atacama» no es exagerar: la pervivencia de esta etnia preinca que mantiene vigencia hasta hoy tendría que llevarnos a reconocer que los actuales departamentos de la costa están históricamente entroncados con la civilización aimara que dominó y domina aún hoy una amplia región del país ${ }^{8}$.

En esta región las migraciones se dan también en la juventud cuando está en capacidad de acumular cierto capital y cuando no ha asumido aún responsabilidades sociales dentro de sus comunidades. El retorno se da en los períodos de 
las fiestas patronales y para contraer matrimonio (E/20, 22, 26). Estamos en una región llena de contradicciones, esplendorosamente atractiva para el turismo internacional, recibe en los lujosos hoteles de las ciudades al más grande flujo turístico del país, pero los efectos de la «industria sin chimeneas» no han redundado en mejora de la situación del campesino pobre de la región, el cual es explotado como objeto folk para postales y campañas de las agencias de turismo.

Los puneños son conocidos como hábiles comerciantes, viajeros y emprendedores. El campesino de las zonas altas cusqueñas ha sido tradicionalmente trabajador lanero, arriero, trajinante y comerciante, desarrollando cierta fiereza necesaria para afrontar los rigores del clima y de una naturaleza agreste. Pero, en esta zona también, y debido a sus especiales condiciones ecológicas, se desarrollaron grandes latifundios que se especializaron en la exportación lanera, tanto de ovinos como de fibras finas de alpaca y vicuña, preciados auquénidos que son propios de esta región. Desde fines del siglo XIX, el Sur Andino abrió sus puertas al capitalismo por la presencia de las casas exportadoras y de los emporios comerciales que se especializaron en el comercio de estos productos, desarrollando así las vías de comunicación en función de sus intereses ${ }^{9}$.

Actualmente el desarrollo es desigual según las provincias y según el estado de las inversiones estatales en infraestructura; en toda la región es notable la inversión en carreteras, a excepción de la circunscripción eclesiástica de la prelatura de Ayaviri. La región cuenta con teléfonos y luz durante 24 horas; todo este desarrollo de infraestructura de comunicaciones, si bien forma parte de la estrategia antiterrorista en su última etapa $(E / 27,28)$, no deja de estar exento de la «generosidad estatal» preelectoral, cuyos costos mensuales (caros) deberá pagar el campesino.

Esta región es ganadera y agropecuaria, pero ambas actividades han sido fuertemente castigadas por los fenó- 
menos recurrentes de las sequías, que han diezmado los ganados y han empobrecido y deteriorado el campo. Esta zona también ha sido el escenario de las grandes movilizaciones campesinas que produjeron el movimiento indígena de comienzos de siglo, cuyos efectos modificaron definitivamente la concepción que los peruanos teníamos del Perú, y dieron origen a un debate y generación de ideas que fue decisivo en la historia política y de las ideas en el país ${ }^{10}$.

En esta zona se desarrolló el latifundismo, por ello también fue una de las primeras regiones en las que se aplicó la reforma agraria en 1969; se expropiaron haciendas insuficientemente explotadas y se cooperativizaron los complejos lanero-exportadores. Sin embargo, la gran debilidad de este proceso de redistribución de la propiedad fue que no se trabajó pedagógicamente sobre la mentalidad de los campesinos cooperativistas, los cuales no conocían otro modelo de relación con la tierra y la empresa que el modelo dejado por el patrón. De esta manera, el campesino actuó como rentista, descuidó las inversiones y el mantenimiento de las instalaciones y resultó depredando la propiedad por la que había luchado durante decenios (E/ 16, 17). Si en las zonas de Sicuani y Ayaviri se puede decir que no hay problema de falta de tierras, la cuestión estriba en cómo hacerlas rentables, de qué manera producir los cambios en las formas de producción y de relación del campesino con la tierra, de cómo se introducen sistemas económicamente rentables de producción agropecuaria moderna que sean, al mismo, tiempo respetuosos del equilibrio ecológico y que satisfagan las necesidades de subsistencia del campesinado (E/17).

Hemos dicho que no existe una política estatal agropecuaria, por eso no hay inversiones en campo surandino, lo poco de inversión que quedaba en los fundos afectados por la reforma agraria se ha esfumado con el tiempo. Como consecuencia lógica, podemos decir que no existe una política de desarrollo integral de la región. Las acciones del Estado tienen frecuentemente un tinte clientelista, las constantes 
inauguraciones de obras de infraestructura, si bien significan progreso para la región, serán pagadas a altos costos por los campesinos y sólo beneficiarán a las empresas que hoy proveen teléfonos, luz, agua, etc. (E/21,28,29).

En este contexto, el campesino surandino tiene que alternar diversas actividades para sobrevivir: al mismo tiempo es ambulante, triciclero y mano de obra migrante que se emplea en las obras de infraestructura; la migración reaparece como única posibilidad de supervivencia. No deja de ser chocante encontrar a campesinos progresistas que nos dicen que aquellos que se quedan en el campo son «los pobres, los viejos, los enfermos y los niños", los mismos que reconocen que las condiciones de supervivencia en la ciudad son infrahumanas (!) $(E / 20,28)$. También es frecuente encontrar lugares en los que durante el año el campo sólo está poblado por niños, mujeres y ancianos, pues la migración en busca de trabajo es muy intensa (E/20).

En todas las regiones visitadas encontramos que la escolaridad de los campesinos se había prolongado mucho. Raramente encontramos jóvenes campesinos con secundaria incompleta, inclusive tuvimos oportunidad de encontrar no sólo a los egresados de los Institutos tecnológicos sino a campesinos que habían seguido estudios universitarios. Aunque ellos valoran sobremanera lo que esta educación formal les aporta, reconocen el apoyo que les da la supervivencia de sus propios valores culturales, no sólo en el campo, sino también en la ciudad, cuando tienen que migrar para conseguir la formación profesional que no encuentran en sus pueblos $(\mathrm{R} / 2,20)$. El no-retorno de las migraciones por estudio se debe a la falta de posibilidades de trabajo en el campo y no a una desvalorización de su propio medio cultural.

Porque se sienten campesinos, y su identidad está ligada a la tierra, comienzan muy temprano a trabajar en ella, tarea que realizan a su retorno del colegio, durante los fines de semana y en las vacaciones. Esta inserción en el trabajo agrícola es producto de su necesidad de aprender un oficio, 
IMELDA VEGA-CENTENO B.

de ayudar al sostenimiento familiar, pero forma también parte de un proceso identificatorio $(R / 5,6)$.

\section{LOS «SALDOS» DEL NARCOTRÁFICO Y EL TERRORISMO}

Actualmente, ambos flagelos han disminuido enormemente, sobre todo en la zona de San Martín (Huallaga central) que tuvimos la oportunidad de visitar. Sin embargo, hace sólo diez años eran los amos supremos de la región, lo cual generó una economía de ficción, con riquezas inconfesables y enormes niveles de gasto. Hoy sólo quedan algunos sicarios que no se sabe exactamente quiénes son y para quién trabajan, pero que están armados; pues tanto el terrorismo como el narcotráfico dieron armas a la población civil, y no todos se han acogido a la ley de arrepentimiento. Son gente que está acostumbrada a disponer de dinero y que está dispuesta a todo para conseguirlo, por eso es necesaria mayor presencia del Estado (E/9). Estos grupos indeterminados, mezcla de terroristas y narcotraficantes, mercenarios, desocupados en general, son los «saldos» del doble flagelo que azotó el Huallaga central, los que serán muy difíciles de erradicar a mediano y largo plazos.

Se sabe que Sendero Luminoso se esta reagrupando por la zona de Saposoa, pero ya no hay sembríos de coca en la región. En este contexto, la recomposición del más mortífero grupo terrorista no deja de ser preocupante, si se tiene en cuenta el grado de pobreza en que está sumida la gente (E/ 15). Aún hay presencia del MRTA en la región, aunque muchos piensan que están debilitados y que su rendición sería posible (E/16). A pesar de la presencia visible del Ejército peruano, en zonas antes inaccesibles subsisten los brotes terroristas y, como se mantiene la extrema pobreza, pervive el caldo de cultivo que les dio origen (E/15).

El narcotráfico está en retroceso, situación que ha sido causada simultáneamente por la enfermedad del hongo en 
los cultivos de coca y por la eficacia de la represión del Estado. Actualmente el Estado peruano tiene mayor presencia en la región, pero la violencia generada por el narcotráfico no ha desaparecido, como recientes confrontaciones en el valle de Sisa lo comprueban (E/16). Quedan también sus trágicas consecuencias. No sólo la economía ficticia que generaron, sino la forma como agravaron los índices de pobreza de los campesinos que se dedicaron exclusivamente al cultivo de la coca (E/15). Es preciso tener en cuenta también que el narcotráfico atrajo su propio flujo migratorio, con gente que trabajaba para ellos en las ciudades de la costa y de la sierra, flujo que se ha quedado en la región. Algunos son ahora trabajadores del campo, pero muchos no tienen medios conocidos de subsistencia (E/14,15).

El narcotráfico y el terrorismo unieron el poder económico y la violencia más irracional y ejercieron un fuerte influjo en los jóvenes de la región en el período anterior (hasta 1992). Toda organización juvenil fue tenida bajo sospecha por las Fuerzas Armadas y muchas debieron desaparecer. Hoy quedan como secuela grupos de jóvenes que se acostumbraron al dinero fácil, que no estudiaron y que están dispuestos a todo a cambio de dinero. Los jóvenes con los que trabajamos habían sido testigos de las extorsiones, secuestros y reclutamiento forzado de otros jóvenes, de cómo el terrorismo estaba aliado con el narcotráfico y la forma cómo los terroristas no practicaban aquello que predicaban sobre la revolución social (R/12). Ellos reconocen que muchos campesinos apoyaron a los terroristas porque venían armados y decían que mañana gobernarían el país. Además de tener poder sobre la vida y la muerte, ajusticiaban a cualquiera sin hacerse problemas, hasta por pleitos menores entre veci$\operatorname{nos}(\mathrm{R} / 21)$.

Tanto en el Huallaga central como en las provincias altas de Cusco y Puno, los jóvenes con los que trabajamos asistieron a la descomposición de los movimientos terroristas, que por rivalidades comenzaban a matarse entre ellos, y la 
IMELDA VEGA-CENTENO B.

forma cómo entraron en pactos vergonzosos con el narcotráfico, haciendo cualquier cosa a cambio de dinero (R/ 12,19). Pero también fueron testigos de cómo los organismos estatales encargados de combatirlos no fueron eficaces, por la corrupción de las Fuerzas Armadas y por la aplicación indiscriminada de la Ley de Arrepentimiento, que se convirtió en una forma de venganza personal, donde cada cual acusaba a quien se le ocurría, sin ninguna responsabilidad frente a sus consecuencias. Estas formas de combatir el narcotráfico y el terrorismo, lejos de generar más justicia, generaron nuevas injusticias $(\mathrm{R} / 12)$.

Los jóvenes recuerdan el tiempo del narcotráfico y del terrorismo como algo atroz, un trauma que no se puede olvidar y que no se debe repetir; muchos jóvenes se comprometieron con ellos por dinero y terminaron muertos. Son tiempos en que se vio corrupción, escándalos y excesos sin nombre. Pero esta experiencia les ha enseñado a organizarse, pues el Ejército no podía estrellarse con todo el pueblo, sino que tenía que venir a dialogar con ellos para combatir juntos ambos flagelos. Los jóvenes que no pertenecían a ninguna institución quedaban a expensas de los narcotraficantes y de los terroristas y eran fácilmente confundidos por las Fuerzas Armadas (R/12,19).

Queda la experiencia de haberse jugado la vida a cada instante. Los que resistieron a las tentadoras ofertas del dinero abundante del narcotráfico necesitarían sentir hoy que todo este riesgo valió la pena. El campesino pobre, que siempre ha vivido de su trabajo y que permaneció en lo suyo, no sufrió la debacle de la derrota del narcotráfico; pero hay toda una generación de jóvenes y adultos que no saben vivir de otra manera, para quienes la derrota de estos flagelos ha sido una verdadera catástrofe (R/19). Esta experiencia ha ensenado que hay que preocuparse por la formación de los jóvenes, para que no sucumban ante las tentaciones del dinero fácil del narcotráfico, que aprendan a respetar su dignidad y la de los demás, que sepan que el narcotráfico y el terroris- 
mo son un crimen contra la humanidad. Todos debemos tener en cuenta que la desesperación de la pobreza puede conducir a cometer errores mayores y que hay que generar espacios de formación y ocupación de los jóvenes, para que puedan insertarse como miembros activos y constructivos de sus comunidades (R/19).

Otra lección de esta historia es que nadie se hace rico de la noche a la mañana, y que el pan se gana con duro esfuerzo, pero con satisfacción y conciencia limpia $(R / 20)$. Hechizados por el abundante dinero del narcotráfico, muchos jóvenes no se dieron cuenta de que estaban caminando hacia la destrucción, la violencia y la muerte. Ahora los jóvenes están mejor informados y no quieren que estos tiempos terribles regresen. En este período de horror abandonaron el departamento de San Martín muchas empresas, bancos y agencias estatales, desaparecieron los préstamos, no habiendo a quién recurrir. Entre tanto, los jóvenes se fueron corrompiendo en discotecas, prostíbulos y fiestas con dudosos artistas que venían del extranjero, causando más desorientación aún $(\mathrm{R} / 19,20,14)$.

En el Sur Andino hubo una presencia desigual del fenómeno terrorista. En la región de Sicuani no tuvo mayor presencia, pero sí en la de Ayaviri y en algunas provincias de Puno. Ante la impasibidad del Estado, Sendero Luminoso penetró en las provincias de Melgar, Sandia y Carabaya, infiltró el campo y asoló pueblos cercanos a las minas. Buscaba cooptar a los líderes campesinos, por eso la JARC tuvo que desaparecer temporalmente, pues sus dirigentes eran seguidos por los terroristas y por la desconfianza de las Fuerzas Armadas hacia las organizaciones populares $(R / 26,27)$. En Sicuani hubo represión indiscriminada, pues las Fuerzas Armadas quisieron confundir el trabajo promocional de la prelatura con el avance del terrorismo. Objetivamente no hubo penetración terrorista, pero muchos agentes pastorales y dirigentes de movimientos laicos sufrieron persecución y cárcel injusta (E/28). Actualmente este fenómeno ha dismi- 
IMELDA VEGA-CENTENO B.

nuido mucho en la región, aunque no se nota una gran intervención estatal para terminar de derrotar el terrorismo, pues no hay proyectos de desarrollo que beneficien y den ventajas objetivas a la población (E/27).

\section{JUVENTUD CAMPESINA Y CAMPOS DE SOCIALIZACIÓN}

Volvamos ahora al sujeto principal de nuestras indagaciones: )de qué joven campesino estamos hablando?.

Hipotéticamente, habíamos afirmado que la familia del joven campesino tiende a ser exigent ${ }^{e}$, que, si bien lo protege y trata de darle todo lo que está a su alcance para que logre superarse, le exige una retribución casi inmediata por las necesidades perentorias de aumentar ingresos familiares y hacer producir la tierra. Dijimos también que el joven campesino iba a la escuela relativamente poco, que había grandes tasas de deserción escolar, sobre todo para las jóvenes mujeres, abandono escolar que era violentado por las exigencias familiares ya mencionadas. El joven campesino trabaja desde muy pequeño en las labores del campo, está inserto laboralmente a través del desempeño de tareas asumidas por la familia, situación que inclusive ha producido la aberración de las actuales "definiciones» estadísticas, donde un niño de seis años que pastorea un hato de ovejas es considerado "población económicamente activa» ((PEA no profesional!) por nuestro sistema social injusto y sus necesidades de medición. En cuanto al tiempo libre, sostuvimos que era casi inexistente, pues, desde muy niño, cuando no está en la escuela debe contribuir al sostenimiento del hogar. Para el sistema de producción, el joven campesino simplemente es un "productor»" .

De esta manera, el joven campesino resulta que es más camipesino que joven, pues desde muy temprano está involucrado en las luchas de su sector social, al margen de sus re- 
querimientos y necesidades de estudio, lúdicas, económicas y de relaciones afectivas que requeriría por su edad.

Cuando tuvimos la oportunidad de cuestionar a los jóvenes sobre este conjunto de campos de socialización, a través del trabajo en grupos ${ }^{12}$, la visión que los jóvenes nos dieron de sus familias resultó ser muy positiva, subrayando características de comprensión, solidaridad, apoyo a los jóvenes, y confianza en los mismos, señalaron el esfuerzo que tienen que realizar para asegurarles un futuro y el valor del apoyo moral que de ellos reciben. Negativamente incidieron en el alto índice de analfabetismo de sus mayores, en la tendencia al abandono del hogar por parte del padre y lo negativo del alcoholismo para un desenvolvimiento familiar armónico ${ }^{13}$.

Teniendo en cuenta la importancia del espacio en que se desarrolla la vida de familia, les preguntamos sobre sus viviendas, pueblos y barrios. Los jóvenes respondieron marcando la diferencia de su hábitat según la región natural en que vivían, señalaron luego que vivían en pueblos pequeños, frecuentemente aislados y marginados, luchando duramente por sobrevivir; por ello subrayaron la importancia de celebrar sus costumbres, realizar trabajos comunales y compartir la liturgia en medio de su pueblo ${ }^{1 t}$. Encontramos, pues, que los jóvenes tenían una visión bastante lúcida de sus familias y una alta estima de sus pueblos como espacio cultural en el que se desenvuelven, lo que les aporta elementos de identidad.

Nuestra pregunta sobre el trabajo fue directa. Los jóvenes nos dijeron que para ellos el trabajo era una necesidad para sobrevivir, un medio que les permitía comprar lo indispensable para cubrir sus necesidades y, si era posible, para lograr los medios para superarse humanamente y realizarse como personas; todos vincularon el trabajo con la necesidad de mejorar su nivel de vida ${ }^{15}$. Todo lo cual nos muestra un nivel de conciencia claro respecto a lo que son sus expectativas laborales y una lucidez no exenta de cierto patetismo cuando nos hablaron de sus requerimientos mínimos frente 
IMELDA VEGA-CENTENO B.

a la oferta de empleo. Por otro lado, cuando les interrogamos sobre su tiempo libre, obtuvimos menos respuestas. Al igual que en los grupos de base y en la encuesta ${ }^{16}$, los jóvenes varones hablan del tiempo libre como el espacio para el deporte; el cual no es practicado de igual manera por las mujeres; éstas tendieron a hablar del apoyo en el hogar, de complementar sus estudios o de realizar tareas comunales. Donde varones y mujeres encuentran un tiempo lúdico común es en las fiestas comunales, en las que participan igualitariamente ${ }^{17}$.

Las respuestas que obtuvimos en cuanto a afectividad y sexualidad no muestran el mismo nivel de apertura. Salvo el grupo «B», todos los demás afirmaron que estaban bien informados por sus padres, que tenían charlas y eventos sobre el tema y que de ello se ocupaban también los centros de salud y la escuela. En el grupo «B» señalaron fuentes de nualinfornuación, indicando que en la televisión, revistas y novelas les venía información equivocada sobre estas materias $^{18}$. Conversando fuera de la reunión con algunos informantes de base, nos afirmaron que «fueron los muchachos de la selva, apoyados por los de Piura, quienes impusieron esta opinión». En realidad no interesa quiénes impusieron la autocensura, porque de hecho existió. Tenemos suficiente experiencia de investigación sobre materias afectivo-sexuales con jóvenes como para afirmar que, en esta pregunta, se ocultó la información.

Si en nuestra investigación sobre los jóvenes de la ciudad, que tienen más medios de información y mayor costumbre de diálogo, encontramos que no tenían una información adecuada en materias afectivo-sexuales ${ }^{14}$, nos resulta inverosímil que los jóvenes de medio rural, con mucho menos acceso a los medios de información especializada y menos hábito de hablar de cuestiones íntimas y personales, sí la tengan. Por otro lado, en otros trabajos sobre los movimientos del formación por la acción, donde analizamos largamente la pedagogía de los movimientos, señalamos noso- 
tros (junto con nuestros jóvenes informantes), la carencia de un área de formación en materias afectivo-sexuales dentro de los mismos ${ }^{20}$. Si fuera cierta la óptima información afectivo-sexual que indicaron los jóvenes en la IX Coordinación Nacional, no habría en las zonas rurales del Perú 250,000 casos de embarazos adolescentes, donde el $40 \%$ de los mismos termina en abortos provocados que ponen en serio riesgo la vida de las jóvenes madres ${ }^{21}$.

En cuanto a las necesidades de migración, los jóvenes afirmaron que migraban en búsqueda de trabajo y de mejor educación, objetivos que se persiguen para poder lograr mejores condiciones de vida y alcanzar la superación, por la que tanto lucharon sus padres. Otros señalaron más sombríamente que se van "porque el campo ya no les ofrece alternativas». Negativamente, indicaron que para muchos la migración conlleva la pérdida y desvalorización de su cultura y cierta falta de amor por la tierra. Creemos que esta visión es bastante completa: habla de las complejidades que vive el joven campesino, empujado a migrar de una tierra a la que ama y de un pueblo con el que se identifica, pero donde, objetivamente, encuentra muy pocas posibilidades de subsistencia. Es interesante decir que un grupo nos señaló también, como ingrediente adicional en las motivaciones para migrar, la necesidad de aventura, sentimiento que está presente en todo joven y que actualmente se halla exacerbado por la forma como subrayan los aspectos de «suerte»los medios de comunicación social ${ }^{22}$.

Preguntados sobre el futuro, los jóvenes nos hablaron en términos de desafío, riesgo, dificultad, complicación, incertidumbre, etc., pero también de posibilidad ${ }^{23}$. Es decir, como jóvenes sienten esa mezcla de miedo y esperanza, de entusiasmo y temor que para todos ha significado el correr la aventura de la vida y, en medio de ella, responder a los desafíos de la historia personal, la historia de nuestros pueblos y la historia del Perú, la que se escribe con mayúscula. 
IMELDA VEGA-CENTENO B.

Nuestro deseo de construir un perfil del joven campesino peruano de fin de siglo fue también sometido a la opinión de los grupos de base, asesores y demás entrevistados; sus opiniones nos permitirán concluir la presente sección. La primera imagen clara que obtuvimos es la del campesino como joven luchador, esforzado $(R / 1,7,11,17,19,21)$, que trabaja la tierra y estudia al mismo tiempo, estudios que tienden cada vez a ser más prolongados, pues completan la secundaria y tratan de seguir estudios superiores en institutos tecnológicos o universidades. Aunque persiste cierta tendencia al abandono escolar, éste ha disminuido, desgraciadamente siempre de modo diferencial según sexo, pues las que más abandonan la escuela para poder ayudar económicamente a las familias son las jóvenes mujeres. Sin embargo, toda esta influencia y frecuentación de la ciudad no los cambia, regresan al campo para tomar las decisiones que comprometen su futuro. En contrapartida, algunos estimulan que sus hijas migren para tener ingresos económicos, pues las mujeres acceden a cierta estabilidad laboral en el trabajo doméstico y mantienen una relación de responsabilidad hacia sus familias en el campo $(R / 1,11,20)$. Estos jóvenes campesinos quieren mayor formación e información, de manera que les permita acceder a cubrir todo el proceso productivo y poder aplicar en sus pueblos las nuevas técnicas y formas de cultivos alternativos. En este esfuerzo deberían incidir las ONGs que tienen a los campesinos como población-objetivo.

El campesino es solidario con su familia y tiende a ayudar a la economía familiar desde muy joven, por eso trabaja al mismo tiempo que estudia, para cubrir sus propios gastos y los de sus menores; sus familias siguen siendo numerosas, aunque han disminuido de tamaño $(R / 7,11,14)$. La búsqueda del progreso humano es otra característica del joven campesino de hoy $(R / 11,17,19)$, en la misma ha aprendido a valorar su cultura y sus más profundos convencimientos le vienen justamente de sus orígenes culturales; podrá migrar, pero 


\section{HACIA UN PERFIL DEL JOVEN CAMPESINO PERUANO}

continuará siendo un hombre del campo (R/11,21). Actualmente tienden a ser más religiosos y su fe alienta sus deseos de superación, son también más participativos, tanto en lo comunal como en lo eclesial (R/31). Su tiempo libre está mezclado con la actividad productiva y recreativa. Por este contacto con el trabajo tiende a independizarse temprano, algunos inclusive forman familia desde los 20 años y antes $(\mathrm{R} / 14,17,20)$.

Muchos campesinos tienden a ser conservadores porque creen que de esta forma están respetando las ideas de sus mayores, pero ahora los jóvenes tienen ideas mucho más autónomas por el acceso a los medios de información, intervienen y actúan con independencia y se está propiciando un clima de creatividad e iniciativa que es sumamente estimulante (R/14). Existen también grupos de campesinos que esperan todo de los políticos y gobernantes, pero cada vez crece más la conciencia de que el futuro se logra con el trabajo y el esfuerzo propio $(\mathrm{R} / 7,14,19)$.

Los que migraron y regresan lo hacen por respeto de sus tradiciones, pero también porque están convencidos de que su futuro está en el campo y que la ciudad no les ofrecerá mejores posibilidades para asegurar sus vidas y las de sus familias. Están dispuestos a asumir temporalmente trabajos muy duros en las minas o en la construcción civil, pero sólo porque de esta manera pueden capitalizar algún dinero para invertirlo en el campo (R14,17).

\section{FISONOMÍA DEL CAMPESINO PERUANO} EN EL UMBRAL DEL TERCER MILENIO

Podemos iniciar nuestras conclusiones provisionales en torno al perfil del joven campesino del umbral del milenio diciendo que los jóvenes campesinos de hoy no tienen aquella imagen doliente y miserable que les dio cierta literatura indigenista de la década del 30: la imagen del campesino 
IMELDA VEGA-CENTENO B.

como un ser arcaico no la encontramos sino en la mentalidad de ciertos funcionarios estatales y algunos representantes de la Iglesia. Sería interesante investigar en profundidad sobre los cambios producidos en las mentalidades campesinas, pues se trata de procesos de cambios culturales, en el sentido más fuerte del término, que se realizan en el mediano y largo plazo. Hipotéticamente, podemos avanzar diciendo que estos cambios de mentalidad serían imposibles sin la irrupción del importante proceso de cambios estructurales en el agro promovido por el gobierno militar de 1968-1975, y cuyo principal proyecto social, a pesar de todos sus límites, fue la reforma agraria de 1969.

El campesino peruano de fin del siglo, si bien ama a su tierra, se pregunta por su futuro, quiere combatir la pobreza con las armas de la técnica y de los avances científicos, es consciente de que éstos no son privilegio de los ricos, sino que están al alcance de las mayorías si consiguen los medios de acceso a la información necesaria. Ante la regresión producida por las actuales leyes laborales y agrícolas del país, son conscientes de las distancias que existen entre campesinos y trabajadores rurales, de los peligros de quedarse sin tierras y no tener más que una mano de obra no calificada que vender. Por eso buscan superarse, buscando mejor capacitación para el trabajo. Tratan de innovar con proyectos productivos modernos y productos alternativos, van adquiriendo mayor conciencia ecológica, pues saben que son responsables de la preservación del medio ambiente $(R / 11,14)$.

A pesar de valorar su cultura, son críticos de los defectos de pasividad, gerontocracia y desconfianza de sus organismos comunales de origen; para cambiar estos aspectos negativos, tratan de asumir responsabilidades dentro de ellos y cumplir eficientemente con sus compromisos locales ( $R /$ 14, E/37). Esta actitud crítica nos lleva a una reflexión de fondo. Para introducirnos en ella, tomemos el ejemplo de la Iglesia católica, la que reconoce que uno de los más graves problemas pastorales en América Latina es no haberse con- 


\section{HACIA UN PERFIL DEL JOVEN CAMPESINO PERUANO}

vertido a las culturas latinoamericanas. Por eso su mea culpa de Santo Domingo (1992) la lleva a proponer como línea de acción pastoral la inculturación.

Desde otra orilla, pero en la misma línea de reflexión, nos encontramos con el drama de J.M. Arguedas: amaba la antropología como ciencia social que pretendía ser contestataria de un orden que, sin embargo, no comprendía $y$, sin comprenderlo, no podía pretender elaborar alternativas. Este impasse provoca la crisis del sentido de su vida, crisis que termina con un balazo en aquel dramático noviembre de 1969. Para quienes comprendimos las raíces andinas del Perú (extendidas a lo largo de las ocho regiones naturales del país), las dolorosas enseñanzas arguedianas, el amoroso sentido crítico de los jóvenes de la JARC nos llena de esperanza y nos hace percibir un futuro más justo y solidario para los hijos del Ande del siglo XXI.

Sin embargo, desde el punto de vista pedagógico, y teniendo en cuenta la importancia de la cultura en toda intervención y acción con los jóvenes campesinos, nos parece muy importante que se plantee un trabajo en torno a los temas de la identidad campesina y el proceso de cambios culturales que producen las nuevas mentalidades campesinas. Los jóvenes campesinos están insertos en una dinámica de cambios sociales que cuestionan su sistema identitario y que frecuentemente lo suplantan con contenidos perniciosos para su supervivencia. Por otro lado, vimos que el campesino podía reproducir los comportamientos del patrón, aunque sean lo más ajeno a sus intereses y a su historia, pero, a falta de modelos identitarios alternativos, reproduce los que le provee la cultura dominante.

Aún no tenemos claro qué es y cómo es el campesino de fin de siglo, y vemos ya surgir al campesino del siglo XXI. El trabajo en torno a los problemas de identidad y cambios de mentalidad nos fuerzan a entrar en una dinámica más profunda, con planteamientos más técnicos y críticos y con la suficiente apertura para responder a cuestiones nuevas 


\section{IMELDA VEGA-CENTENO B.}

de manera totalmente inédita. El trabajo en torno a estos temas es imprescindible para que el futuro sea nuestro y para que, finalmente, los jóvenes campesinos del tercer milenio puedan ser los actores de la historia del Perú como lo fueron sus abuelos. 


\section{Notas}

1 Vega-Centeno, Imelda, Los pobres, los jóvenes y la Iglesia, MIEC-JECI, Lima, 1984; "América Latina: es peligroso ser jóvenes", en Boletín ICLA nE 67, Lima, 1985; Mozimiento universitario y cambio social: los casos de Bolizia y Paraguay, MIECJECI, Lima, 1986; "Ser joven y mestizo: crisis social y crisis cultural en el Perú", en Márgenes, año II, nE 3, Lima, 1988; Amor y sexualidad en tiempos del sida: los jóvenes de Lima metropolitana, Minsalud, (Programa Nacional de Control del Sida y ETS), Lima, 1994.

2 Cuadro: Juventud latinoamericana: campos de socialización y sistema de producción, Contratapa Cuaderno NE 3.

3 Vega-Centeno B., Imelda, Eva-

luación del trabajo de la JARC en el Perú (solicitada por Entraide et Fraternité, Bruselas-Bélgica), Lima, septiembre de 1997.

4 Ver Vega-Centeno B., cf. "Anexo" nE 2 A, Guía de reuniones con grupos de base.

5 Ver Ibid., "Anexo» nE 2, C., Guía de preguntas para el trabajo de grupos: 6 de agosto de 1997.

6 Geografia del Perú: Las ocho regiones naturales del Perú, Ed. Universo, Lima, 1981.

7 A partir de este párrafo tomamos algunos elementos de nuestros "Informes regionales", los que constituyen la primera parte (caps. 1, 2 y 3) de nuestra Evaluación del trabajo de la JARC ya citada.

8 Van Kessel, Ian, “Ecología y orientación: problemas de identidad cultural de los aymaras chilenos contemporáneos", Chungyará nE 6 (revista de la univesidad de Tarapacá), 1980.

9 Rénique, José Luis, Los sueños de la sierra: Cusco on el siglo XX,

Ed. CEPES, Lima, 1991; Flores Galindo, Alberto, Arequipa y el Sur Andino, Ed. Horizonte, Lima, 1977.

10 Vega-Centeno B., Imelda, $L a$ construcción social de la sociología: invitación a la crítica, Ed. F.F. Ebert, Lima, 1996 (ver Cap. II).

Vega-Centeno, Imelda, Los jóvenes, los pobres y la Iglesia, Miec-Jeci, Lima, 1984. Véase sobre todo el Cap. I. 11 Ver también el Cap. I, "Marco teórico-interpretativo", de nuestro Amor y scxualidad..., Lima, 1994.

12 IX Coordinación Nacional de la JARC, día 6 de agosto de 1997. Tema: “¿De qué juventud rural hablamos?» Expositora: Imelda Vega-Centeno. Cf. "Guía para el trabajo de grupos», en Vega-Centeno B., Imelda, Evaluación del trabajo de la JARC en el Perú, ANEXO 2-C, Lima, 1997. 


\section{IMELDA VEGA-CENTENO B.}

13 Ver ACTAS de la IX Coordinación Nacional, "Informe del trabajo de grupos: día 6 de agosto de 1997, pregunta 1.

14 Ver, Ibid., pregunta 2.

15 Ver Ibid., pregunta 3.

16 Estos fueron otros de los instrumentos metodológicos que utilizamos en el trabajo de evaluación ya citado.

17 Ver ACTAS de la IX Coordinación Nacional de la JARC, pregunta 4.

18 Ver Ibid., pregunta 5.

19 Vega-Centeno B., Imelda, Anor y sexualidad en tiempos del sida: los jóvenes de Lima metropolitana, Min-
Salud, Lima, 1994. Véase sobre todo el Cap. III.

20 Vega-Centeno B., Imelda, Los jóvenes, los pobres y la Iglesia, Miec-Jeci, Lima, 1984. Véase sobre todo el cuaderno NE 3.

21 INEI, Censo 1993, Informe Sectorial de Salud.

22 Ver Actas de la IX Coordinación Nacional de la JARC, pregunta 6.

23 Ver Ibid., pregunta 7. V Conferencia General del Episcopado Latinoamericano (Santo Domingo), Conclusiones: Nueva evangelización, promoción humana, cultura cristiana, Conferencia Episcopal Peruana, Lima, 1992. 